\title{
Analysis and Research on Current Juvenile Delinquency
}

\section{Fan Jiang}

School of Arts and Law, Wuhan University of Technology, Wuhan, P. R. China

Email address:

\section{To cite this article:}

Fan Jiang. Analysis and Research on Current Juvenile Delinquency. International Journal of Economics, Finance and Management Sciences. Vol. 6, No. 1, 2018, pp. 23-26. doi: 10.11648/j.ijefm.20180601.14

Received: January 20, 2018; Accepted: February 2, 2018; Published: March 5, 2018

\begin{abstract}
It has been more than 30 years since China started to study the issue of juvenile delinquency. And research results from all dimensions currently show initial scale and efficiency. With the perfection of the legislation to teenagers and continuously-profound research on this issue, juvenile delinquency has got a quite good control. However, the issue of teens-related crimes in China still is not thoroughly optimistic at the present time due to effects from these factors including development and transformation of the society, as well as family problems, physical and mental issues of the young boys and girls, etc. This paper tries to analyze the features about juvenile delinquency and its causes in China at present from status quo of juvenile delinquency and relevant data, and tries to come across with solutions for the existing issues.
\end{abstract}

Keywords: Juvenile Delinquency, Effectiveness, Precaution

\section{Introduction}

It is worthy for everybody to concern the issue of how to make teenagers enjoy a healthy growth and stop them from committing a crime. From the perspective of harm, not only does juvenile delinquency affect social security, but also does harm to physical and mental health of teenagers. What's worse, its explosive spread makes people worry a lot. Studying and analyzing juvenile delinquency can provide national juridical practice with good reference and promote many an effective approaches and measures which impede young boys and girls from offence to be listed juridical practice. Additionally, it is also significantly meaningful for national law-making organs to correct and supplement regulations with respect to crimes of teenagers.

\section{Status Quo and Features of Juvenile Delinquency}

\subsection{The Present Situation of Juvenile Delinquency}

Among domestic researches on teens-related crimes, those based on basic conditions and main features of juvenile delinquency are most detailed and profound. In addition to LU Qi, there are also other research representatives. Their studies show that the total number of juvenile crime in China had a continuing decline after 2009 , and the rate of criminal offence went down overall after 2009, but since 2010, the speed of decrease had started to slow down. (consult Table 1)

Table 1. Statistics of Teenagers' Crimes from 2007 to 2016.

\begin{tabular}{|c|c|c|c|c|c|c|c|c|c|c|}
\hline Year & 2007 & 2008 & 2009 & 2010 & 2011 & 2012 & 2013 & 2014 & 2015 & 2016 \\
\hline Number of juvenile delinquency cases & 316397 & 322061 & 302023 & 287978 & 282429 & 282990 & 265439 & 249576 & 236341 & 204657 \\
\hline $\begin{array}{l}\text { Number of juvenile delinquency cases as a } \\
\text { percentage of total criminal cases }(\%)\end{array}$ & 43.90 & 41.93 & 39.39 & 36.94 & 33.62 & 28.69 & 27.82 & 24.39 & 21.50 & 18.59 \\
\hline
\end{tabular}

From the national courts' trial regarding young persons' crimes in the period of 2007 to 2016 (these data comes from bulletins of the Supreme People's Court), it is obvious that the number of young people's criminal offence started to have a continuing decrease year after year from $43.90 \%$ of 2007 ; up to 2012 , it had dropped to less than $30 \%$; subsequently, another decrease came, and went down to $18.59 \%$ till 2016. (See Figure 1) 


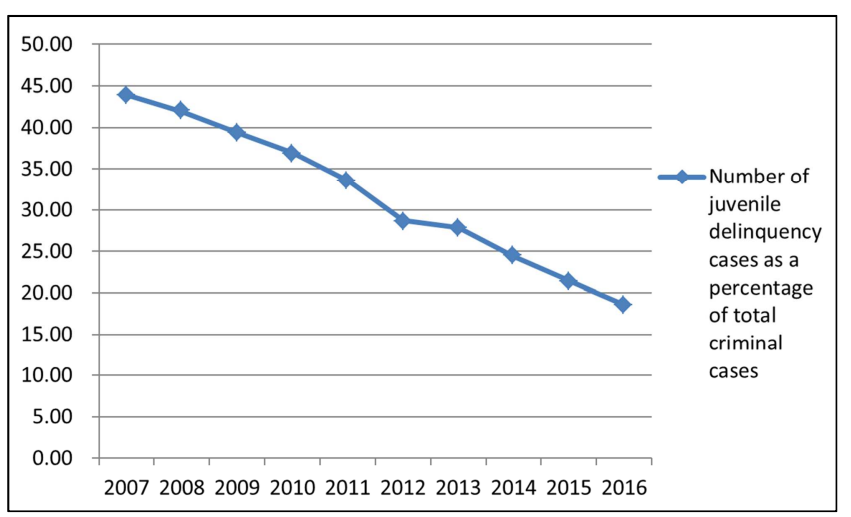

Figure 1. Statistics on the Changes of Proportion of Juvenile Offence in Total Criminal Cases in 2007-2016.

\subsection{Features of Juvenile Delinquency}

\subsubsection{Young Age Tendency of Juvenile Delinquency}

Professor GUO Xiang, Executive President of Juvenile Delinquency Association of China, pointed out that the peak age in which teenagers initially do something illegal is at 12 to 17 ; and the peak age for primary crime is at 14 to 18 ; and that for violent offence and sexual wrongdoing is usually at 15 to 25. According to the data of 2007 to 2016 from the bulletins about the minors' crimes issued by the Supreme People's Court, the peak age of crime of young boys and girls focuses on 18-25. (See Figure2)

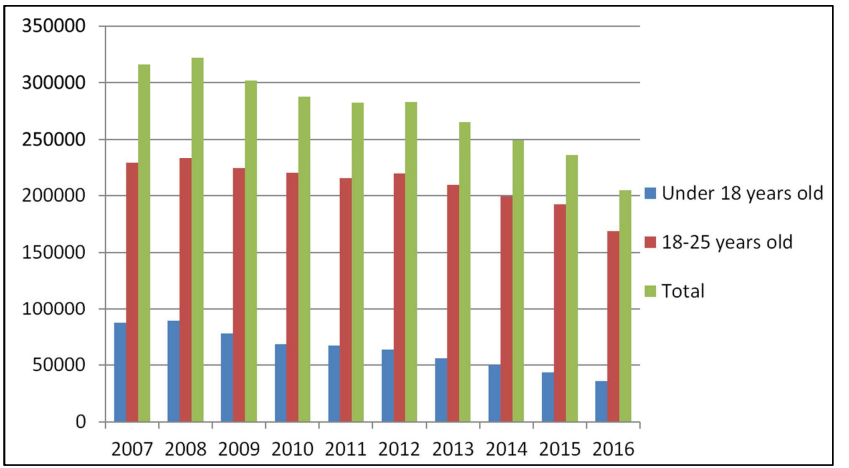

Figure 2. Statistics on the Changes of Proportion of Juvenile Offence in Total Criminal Cases in 2007-2016.

The low-age tendency of teens' offence here mentioned refers to the age of initially committing crimes and peak age of offence get more and more earlier. Some materials indicate that the low-age tendency of teens' offence in China has a regional feature. For example, juvenile offenders in special economic zones in coastal area and medium and large cities are more than in mainland and villages. Specifically, criminal rate of students from primary school and middle school shows an increasing trend, and their means of crime develop towards violence and intelligence. Those minor offenders normally presented bad conducts at 10 to 12 years old; started to do something unlawful at the age of 13 to 14; and frequently committed offence from 14 to 17 ages; as well as became main social criminals after 18 years old ${ }^{1}$. Generally speaking, the low-age tendency of minor crimes becomes a common trend as the social production standard goes up and personal physical development starts earlier.

\subsubsection{Lower Education of Juvenile Offenders}

Among these minor criminals, the mass of them are students dropping out of schools, or dropouts. They possess incomplete knowledge structure and are low in overall cultural quality. Beijing City made statistics for the cultural degree of young boys and girls who did wrongs in 2013, which suggested that illiterate and semi-literate offenders accounted for $9 \%$, criminals with primary school diploma accounted for $34 \%$, criminals with middle school diploma accounted for $38 \%$, criminals with high school diploma accounted for $10 \%$, criminals with secondary school diploma accounted for $6 \%$, and others accounted for $4 \%{ }^{2}$. (As shown on Figure 3)

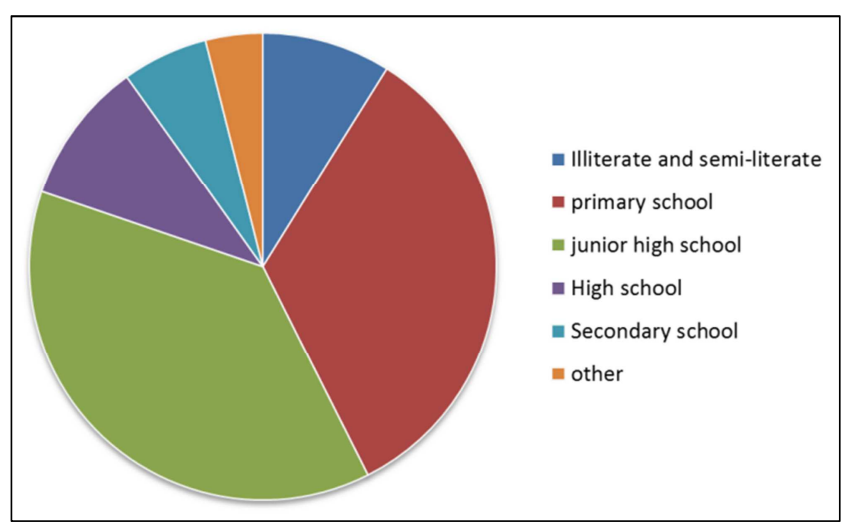

Figure 3. 2013 Beijing City Juvenile Delinquency Chart.

\subsubsection{Gang Illegal Activities}

Gang crime means that a lot of young boys and girls work together to commit a crime. Pursuant to the analysis from physical and mental perspectives, to begin with, teenagers at this stage are easily affected by the plots of movies like Youth and Danger and then form cliques to fights due to incomplete formation of the correct three views, even developing into gang brigandage and robbery. Secondly, with the increase of the society's precautionary awareness, the success for teens to carry out wrongdoings alone goes down. While it shows a considerable growth when these bad guys cooperate, and exchange experience and encourage each other during illegal activities. Therefore, they often choose to commit a crime by a gang.

\section{Analysis for Reasons of Juvenile Delinquency}

\subsection{Personal Factors of Teens}

In the first place, teenagers are curious about almost

1 LUO Dahua: Analysis for Psychology of Juvenile Delinquency, Knowledge Press, the first issue of July in 1982.

2 ZHUANG Xuan: Status Quo and Reasons of Juvenile Delinquency reprinted on the People's Daily on September 29, 2014. 
everything at such age, but are not rich in social experience, not strong in the ability of distinguishing the truth and false as well as the right and wrong, and unable to rationally judge some things that are slightly complicated. In that case, they would attempt in person, and finally embark on a road of crimes in the case of not completely understanding reasons.

In the second place, some juveniles engage in offence only for sensation seeking. Namely, for the sake of seeking stimulation, they would blindly follow other members without a definite criminal purpose and motivator because of the effect by criminal gangs. Besides, teens always deal with matters under influence of emotions, and can not consider deeply and carefully first when handling everything. What's more, from the physical perspective, youth age is the one in which young boys and girls show the strongest psychological inversion. For instance, upon suffering offence from themselves or their friends, they would have an idea of not forgiving easily and are easy to rage. These aforesaid all can occasion an increasing growth of criminal rate of young boys and girls.

\subsection{Family Reason}

Juvenile offence to a large extent results from family effect. The unreasonable education modes of family have a remarkable influence on the crime of teenager. The left-behind children are easy to embark on the road of illegal activities. Such cases in our life are in great number. Also, too much love of family make children easily form a habit of bossiness, recklessness, lazy good-for-nothing and even doing all manner of evil. Furthermore, since the left-behind children are not in a restricted state because of not being loved and concerned by parents often as well as intense insufficiency of family education, they are more likely to present themselves with crimes. Apart from the aforesaid, parents' divorce causes loss of family warmness, letting them have an unbalanced mind, which further triggers the occurrence of criminal acts. Hence, the study on reasons of teenagers' delinquency attaches great importance to family education.

\subsection{Absence of Moral Education in School}

Schools' duty should not merely focus on imparting vocational skills to students, but should attach great importance to the cultivation of moral qualities and formation of correct outlook on life. However, nowadays many teachers just pay more attention to enrolment rate, which leads to ignorance of education to teenagers' law, dream and morality. Thus, the younger generation does not behave as they are expected.

What's worse, class separation is like an intangible label for students because those who are good at learning are arranged to gather a better class and assigned excellent teachers. Off course, those with bad score are asked to enter a worse class. That means schools only concern students' learning and neglect the development of other aspects. As a result, though some of them do well in learning, they may be not good in moral quality. While those arranged in a worse class are more like to have a negative emotion, they will give up themselves, drop out of schools, hate learning and so on when feeling hopeless. Some of them even carry out illegal activities because of having nothing to do after entering society

\section{Countermeasures and Suggestions for Prevention of Juvenile Delinquency}

\subsection{Juveniles Should Strengthen Self-Precaution}

Teens' precaution to offence consists of subjective self-precaution and objective precaution. Objective precaution would become effective with the help of external causes, but subjective self-precaution is the determining factor and it therefore needs teenagers to intensify their self-precaution.

So how to make the precaution for juvenile delinquency work more effectively? Initially, family, school and society ought to give more love and attention during the growth of young boys and girls, to guide them to form a correct outlook on life. Normally, they are supposed to have their own pursuits in life. However, some are confused and perplexed when facing choices in life, especially those who getting a lower education. In such situation, families should encourage their children to have a positive attitude towards life and be hopeful to life; schools ought to provide them with positive education; and society should take the obligation to create a good environment for teens. Secondly, minors do not have a good ability of self-control, but have a limited ability of telling the truth and false, and are more likely to be affected by the external temptations. Therefore, they ought to be required to learn about laws and social norms to enhance their cognition and abilities of self-protection and right and wrong distinguishing as well as increase and cultivation of personal qualities. This is the fundamental measure for juveniles to prevent themselves from pursuing wrongdoings.

\subsection{To Intensify the Family Effectiveness for Prevention of Juvenile Delinquency}

Family is the key to protect teenagers from crimes. Family plays a critical role in that whether their daily behaviors are right or can be corrected in time. The prospect for children to commit a crime will be higher if they suffer absence or lack of love and concern from families, according to the relevant investigations.

Fundamentally, family is a vital place for children to grow healthily. So there is no doubt that parents ought to undertake the responsibility to educate their kids. First, parents are required to learn about knowledge with respect to laws and have an awareness of legal system. Second, parents are supposed to understand their own importance fully, enhance themselves and their ability of preventing themselves from offence, so as to set a good example for their kids ${ }^{3}$. Additionally, society also should be asked to take the responsibility for crime avoidance. For example, social organizations should actively supply assistance for the

3 KANG Shuhua: The Whole Book of Prevention of Juvenile Delinquency and Legal Education, the $851^{\text {st }}$ page of the issue in 1999, Xiyuan Press. 
families with difficulties or troubles to improve internal surroundings of family and make the capability of family to protect young kids from committing a crime raise. Furthermore, the relevant legal regulations should be used to make up for the deficiency of family's education. For instance, our society should proactively shoulder the obligation of educating young people when there is a family in which the environment does harm to his/her growth, so as to minimize the risk of juvenile delinquency.

\subsection{Prevention of Juvenile Delinquency Based on Education}

To enhance school education stops the examination oriented education from becoming the baton of it. Schools should view education of mental outlook and psychological health as significance when imparting cultural knowledge. As we all know that accumulation of cultural knowledge just takes time but the quality to be kind-hearted and good and honest is not easy to be educated just using time, and moral education usually takes more time and energy than that of knowledge, just like Chinese saying goes that it takes ten years to grow trees, but a hundred to rear people. Minors are the future of our nations and country and their positive thought is the foundation of our state. Accordingly, schools inevitably ought to think moral education first and see cultivation of juveniles who have healthy psychology and positive spirit as the priority and objective of education.

\section{Conclusion}

Enhancing the research on the law of prevention of juvenile delinquency and carrying on with innovation are the purposes for legal professionals, and more are the important measures to intensify and innovate social management. It is of great significance. Study on law of juvenile has a long way to go, and that young persons can have a healthy growth is responsibility for all of us. In particular those engaging in law should completely and respectively display their own speciality, and make use of their advantages of rich theories and resources from practices and do everything they can to facilitate the research results to be deepened, exchanged and shared, so as to make considerable contributions to healthy growth of young boys and girls, peace and harmony of society as well as lasting stability and durable peace of our nation.

\section{References}

[1] LIU Hao: Summary of Research on Juvenile Delinquency of 2014 [J], Youth Research, 2015, (1): 78-83.

[2] CHEN Cixin: Legal Education and Crime Prevention for Juveniles [J]. Journal of Japan Chuo University, 2010 (9).

[3] JIN Xiaohong: Sociology Research on Offence of Urban Mobile Juveniles [M]. Wuhan: Huazhong University of Science \& Technology Press, 2014.

[4] CHEN Guixiang: Research on Juvenile Delinquency [J]. legal System and Society, 2012 (5): 279.

[5] CAO Lei: Discussion of Cost Analysis and Control on Juvenile Delinquency in China. Anhui University, 2013.

[6] MA Rongchun: Research on Criminal Reasons of School Teenagers and School Countermeasures. Issues about Juvenile Delinquency. 2012 (7).

[7] GUAN Ying: Foundation to Prevention of Minor Crime is from Family reprinted on Research on Prevention of Juvenile Delinquency, the $2^{\text {nd }}$ issue of 2013.

[8] LI Exian: Internet Inducements and Countermeasures of Chinese Juvenile Delinquency [J]. Legal System and Economy, 2016 (08):178-180.

[9] LI Dan: Function of School Physical Education for Prevention of Juvenile Delinquency during Juveniles' Socialization [J]. Legal System and Society, 2017 (29): 148-150.

[10] YANG Zonghui, TIAN Ye: Study on Countermeasures Preventing Juvenile Delinquency of China [J]. Journals from Hubei University of Police, 2016, 29 (04):45-50.

[11] LIN Yumin: Survey on Status Quo of Modern Juvenile Delinquency of China [J]. Journals from Fujian University of Police, 2017, 31 (02): 33-46. 